\title{
Contribution to Harmonic Depollution Control by the Use of Adaptive Hybrid Filter Type TLC: Case of Control by Modulated Hysteresis
}

\author{
Luc Vivien Assiene Mouodo ${ }^{*}$, Jean Gaston Tamba², Olivier Sosso Mayi ${ }^{3}$, Lawren Bibaya ${ }^{3,4}$ \\ ${ }^{1}$ Laboratory of Modeling Materials and Methods of the National Higher Polytechnic School, Douala University, \\ Douala, Cameroon \\ ${ }^{2}$ Institute of Technology, Douala University, Douala, Cameroon \\ ${ }^{3}$ Higher Normal School of Technical Education, Douala University, Douala, Cameroon \\ ${ }^{4}$ School of Electrical and Electronic, Engineering University, Beijing, China \\ Email: *assienemouodolucvivien@yahoo.fr
}

How to cite this paper: Mouodo, L.V.A. Tamba, J.G. Mayi, O.S. and Bibaya, L. (2020) Contribution to Harmonic Depollution Control by the Use of Adaptive Hybrid Filter Type TLC: Case of Control by Modulated Hysteresis. Energy and Power Engineering 12, 578-602

https://doi.org/10.4236/epe.2020.1210036

Received: August 31, 2020

Accepted: October 26, 2020

Published: October 29, 2020

Copyright (C) 2020 by author(s) and Scientific Research Publishing Inc. This work is licensed under the Creative Commons Attribution International License (CC BY 4.0).

http://creativecommons.org/licenses/by/4.0/

\begin{abstract}
In this article, we propose a topology of a TLC-HAPF power filter as a harmonic compensator for an optimization of the pollution control of electrical networks. This filter consists of an active part and a passive part in order to reduce or limit switching losses during current injection into networks thanks to its TLC module. This topology also provides solutions dynamic performance issues, resonance and lack of compensation capacity for imbalance cases. It also offers a greater range of compensation than conventional active models which do not offer as well as an intermediate circuit voltage in the order of $105 \mathrm{~V}$ to $109 \mathrm{~V}$ relatively lower than others models $(600 \mathrm{v})$. A modulated hysteresis control of this topology is therefore also developed in this article and allows to obtain a network analysis on the three phases at three levels: source side, load side, and finally at the connection of the filter to the network, allowing to specify for these different positions the value of the current spectrum and its THD at this well-defined moment.
\end{abstract}

\section{Keywords}

Hybrid Adaptive Active Filter, Modulated Hysteresis, THD, Harmonic

Pollution Control

\section{Introduction}

Nowadays, the increasing use of power electronics devices in electrical systems has led to more and more problems related to harmonic disturbances or distor- 
tions in electrical networks. This phenomenon affects all industrial sectors (use of dimmers, rectifiers, variable speed drives, etc.) and domestic (televisions, consumer appliances, etc.) [1]. Harmonic distortion is generated by non-linear loads connected to the network and which absorb non-sinusoidal currents [1] [2] [3] [4]. These current harmonics will in turn generate harmonic voltages at the various points of connection to the network. For other electrical equipment connected at these points, this harmonic pollution has harmful effects. Among these effects, we can in particular quote the distortion of the network voltage at the connection point when the energy distributor is required to supply its own voltage. This pollution can also lead to the heating of cables and electrical equipment or even to the sudden shutdown of rotating machines, or even the total destruction of all this equipment. To reduce or eliminate these disturbances and thus improve the quality of the distributed energy, several solutions exist [1] [5].

- reducing the short-circuit impedance,

- modification of the polluting static converter in terms of topology and/or control in order to intervene directly at the source of harmonic disturbances,

- filtering devices.

The use of filtering devices such as so-called resonant and or damped passive filters can thus prevent harmonic currents from propagating in electrical networks [1]. They can also be used to compensate reactive power. However, passive filtering poses certain problems [6] [7] [8] [9]: lack of adaptability during variations of the network impedance, of the load and possible resonance with the network impedance and in certain unfavorable cases where this resonance is excited. This can cause a high harmonic voltage and a high harmonic current in the filter capacitance and in the network. Thus, this solution has a major drawback which may be intolerable in these particular circumstances [10] [11] [12] [13]. Another solution is to implement active filtering to avoid the drawbacks of passive filters. However, active filtering also has its specific drawbacks, in particular its high cost for industrial applications [14] [15] [16] [17]; the dimensioning of the power converter of the active filter can then be relatively high. For this major reason, the applications of active power filters in electrical systems are still limited today [18] [19] [20] [21]. The disadvantages of passive filters and active filters can be simultaneously limited by using new topologies of active filters, called hybrid filters. Hybrid active filters are considered today as a solution which makes it possible to reduce the sizing and consequently the cost of active filters [22] [23] [24]. The hybrid filter consists of the association of passive filters, intended to absorb the current harmonics coming from the polluting load, and of a low power active filter. The work presented in this paper generally shows in a first section the review of the literature and the state of the art on the solutions to harmonic pollution and their evolution over time, in the second section a modeling of the architecture and functionality of the TLC-HAP model, followed by an implementation of the modulated hysteresis control which presents the evolution of the current spectrum on the network at 3 essential positions: load side, network side, and at the level of the injection of the filter on 
the electric line with a value in THD each time. This implementation is done in the MATLAB Simulink environment.

Our work is aimed at improving the performance of active filtering through structures but also through the control algorithm, but this does not require us to review the usefulness of these structures. However, several industrial applications developed nowadays for high powers in medium voltage (MV), a field for which current power components cannot meet with standard configurations. This is how multi-level converters (CMN) have been introduced in recent years to overcome this problem. Current industrial applications for these converters revolve around active and hybrid filtering more and more today including other needs before the following: Interfacing for renewable energy, HVDC (High Voltage DC transmission), FACTS (flexible AC Transmission Systems), UPFC (Unified Power Flow Controllers), electric traction and static compensation. Converters used in industry as standard products are:

1) NPC: Neutral Point Clamped, (also known by Diode clamped), it is a structure which was introduced by Nabae in 1981 [25], since then several works have been carried out on this type of converter [26] [27] [28] [29]. The 3L (3 level) -NPC is the most used in MV for controlling motors, but the major problem with this topology is the balancing of the DC voltages and this is why its use is limited to 3L. In addition, a fairly large output filter is required [30].

2) FLC: FLying Capacitor or FC, developed by Meynard and Foch in 1992 [21], improved, by the same authors, by another structure in 2002 [22]. It is also a popular topology used for controlling motors as well as for active filtering [23] [24] [25]. The direct command of a 4-level structure is done in [26] [27]. Given that the value of the capacitance is inversely proportional to the frequency, this topology is preferably intended for high frequencies.

3) SCHB: Cascaded H-Bridge series presented by Hammond in 1997 [28], an evolution was proposed in 2006 by Ceglia et al. [29]. Power and voltage are easily matched given the modular nature of these converters. The most used is 5L-SCHB. The energy stored in the LC filter is reduced to $80 \%$ compared to NPC [20].

\section{Problems of Electrical Pollution}

\subsection{Harmonic Disturbances}

The use of electrical equipment involves static converters in electrical energy conversion plants and in recent years a significant increase in the level of harmonic pollution. They have contributed to the deterioration of the quality of the current and the voltage of the distribution networks. The main sources of harmonics are fluorescent lighting fixtures, computer equipment, household appliances (televisions, large numbers of household appliances), electric arcs and all static converters connected to networks such as rectifiers and inverters. All these systems contribute to the harmonic pollution of the network to which they are connected. Indeed, these systems absorbing non-sinusoidal currents, even if 
they are supplied by a sinusoidal voltage. This electrical equipment is intended as non-linear loads emitting harmonic currents whose frequencies are integers which are multiple or not integers of the fundamental frequency. The presence of current or voltage harmonics leads to harmful effects on the distribution network, for example [1] [3] [4] [5] [6] [7]:

- Heating of conductors, cables, capacitors and machines due to additional copper and iron losses.

- Interference with telecommunications networks, caused by electromagnetic coupling between electrical networks and telecommunications networks which can induce significant noise in the latter.

- The malfunction of certain electrical equipment such as control and regulation devices. In the presence of harmonics, current and voltage can change sign several times during a half-cycle. Consequently, equipment sensitive to the zero crossing of these electrical quantities is disturbed.

- Resonance phenomena. The resonant frequencies of the circuits formed by the inductors of the transformer and the capacitances of the cables are normally quite high, but these can coincide with the frequency of a harmonic. In this case, there will be a significant amplification which can destroy the equipment connected to the network.

- The degradation of the precision of measuring devices.

- Interference induced on communication lines, particularly electromagnetic radiation.

Different criteria are defined for these disturbances. The THD and the power factor are the most used to quantify respectively the harmonic disturbances and the non-active power consumption. The THD represents the ratio of the rms value of the harmonics to the rms value of the fundamental. It is defined by the relation:

$$
\mathrm{THD}=\sqrt{\frac{\sum_{n=2}^{\infty} X_{n}^{2}}{X_{1}^{2}}}
$$

with $X$ either a current or a voltage.

\subsection{Electrical Network Depollution Solutions}

Two types of solutions are possible. The first consists in using static converters which pollute less or less, while the second consists in the implementation of a filtering of the harmonic components. The first class of solutions is concerned with the design while the second is to compensate for harmonic currents or voltages [9]. Two groups of pollution control solutions to compensate for all disturbances can be distinguished: traditional solutions and modern solutions.

\subsubsection{Traditional Solutions}

In particular, this involves implementing the following means:

1) Statocompensator: this is a compensation method used to record the power factor, 
2) Passive filter: the oldest for the treatment of current harmonics. It consists of trapping harmonic currents to prevent them from propagating to the rest of the network.

\subsubsection{Modern Solutions}

These solutions are proposed as effective solutions for cleaning up electrical networks in order to deal with the drawbacks inherent in traditional solutions such as passive filters (not adaptive to variations in the load and the network, resonance phenomena). Among all modern solutions, there are two types of structures conventionally used:

- The active filter (series, parallel or even combining the two),

- The hybrid active filter (series, parallel).

The purpose of these active filters is to generate either currents or harmonic voltages so that the current or voltage becomes sinusoidal again. The active filter is connected to the network either in series (FAS) or in parallel (FAP) depending on it is designed respectively to compensate the harmonic voltages or currents, or associated with passive filters.

To provide consumers with quality electrical energy, even under the most disturbed operating conditions, active filters are offered as solutions for cleaning up electrical networks [10]-[15]. In the following, various topologies of usual active filters are presented.

\subsection{Configuration of Hybrid Filters}

In recent years, many hybrid filter topologies associated with different control strategies have been presented in the scientific literature in order to improve the quality of energy but especially to reduce the sizing of the active power filter and therefore its cost. Hybrid filters can be classified according to the number of implemented in the topology studied (active filters and passive filters), the system treated (single-phase, three-phase three-wire and three-phase four-wire) and the type of inverter used (voltage structure or current). Figure 1 presents some hybrid filter configurations according to the type of analysis system and the associated elements [17].

\subsection{Hybrid Active Filter Control}

The performance of hybrid active filters strongly depends on several factors [7]:

- the control mode used (modulated hysteresis) for generating the power switch control commands,

- the performance of the capacitive reservoir voltage regulation loop.

Active hybrid filtering indeed requires high real-time performance when installing the control, given the frequencies of the harmonics to be generated.

In this paper we will theoretically study the model of hybrid active power filter with LC coupling, (TCLC-HAPF) controlled by thyristor. And will be intended to clean up a three-phase three-wire electrical network connected to three-phase non-linear loads of the bridge type rectifier, discharging into a load $\mathrm{R}$. 


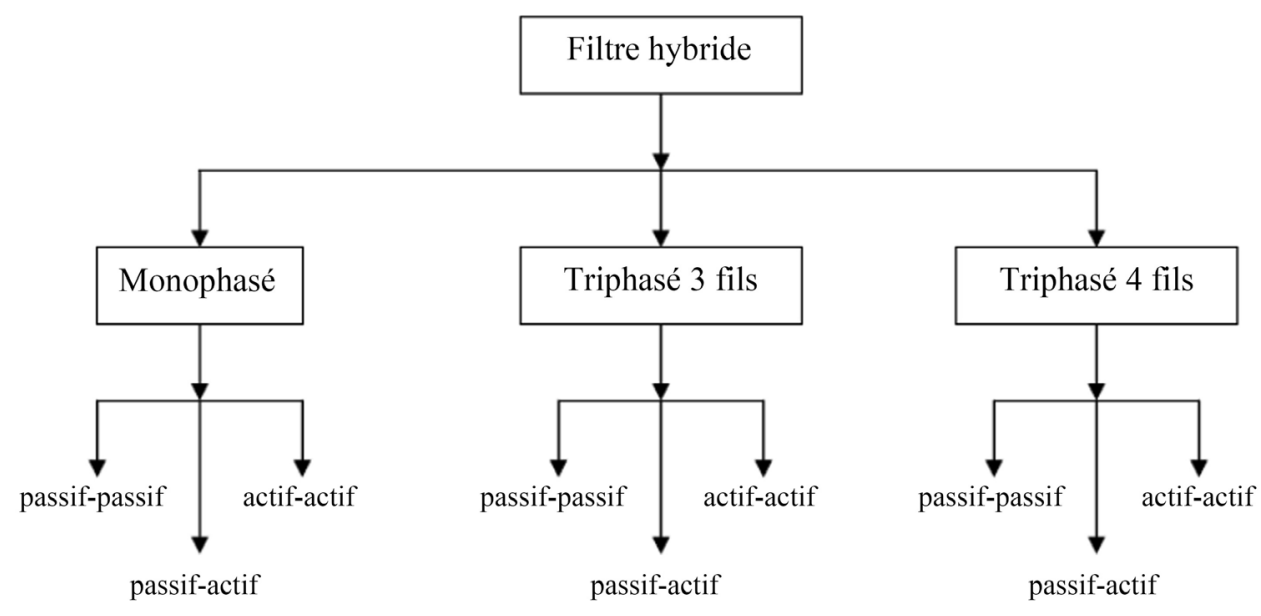

Figure 1. Classification of hybrid filters.

\section{Modeling and Ordering Methods of the Active Adaptive Hybrid Filter}

The insertion of hybrid adaptive active filters in electrical networks is a very reliable solution in the pollution control of harmonic currents produced mainly by non-linear loads and circulating through electrical networks. Indeed, the choice of manufacturers to use hybrid filters has been evaluated in recent years due to the advantages that this structure provides compared to the classic active shunt filter [20] [22]:

- Possibility of using less expensive power semiconductors,

- The voltage $V_{d c}$ lower than for a shunt filter,

- The energy stored in the $C_{d c}$ storage element is lower,

\subsection{Structure of the Thyristor Controlled LC Coupled Hybrid Active Power Filter (TCLC-HAPF)}

The following figure (Figure 2) shows the structure of the TCLC-HAPF in which the index " $X$ " represents the phase A, B and C, in the rest of the analysis, $V_{s x}, V_{x}$ and $V_{i n v x}$ are respectively the voltage source, the load voltage and the output voltage of the inverter, $I_{s x}, I_{l x}$ and $I_{c x}$ are the load and compensation source currents respectively, $L_{s}$ is the impedance of the transmission line. In Figure 2, the TCLC part of the TCLC-HAPF filter is composed of a coupling inductor $L_{c}$ a $C_{P F}$ capacitor in parallel with a reactor controlled by an $L_{P F}$ thyristor. The active part of the filter consists of a voltage source inverter with a DC link capacitor.

\subsubsection{Attenuation of Harmonic Current Injection in the TCLC Part and Filtering Characteristics}

In Figure 2 the thyristors (T1x and T2x) for each phase of the TCLC part can be proposed as a pair of bidirectional switches; which would generate a low order harmonic current when the switches change state.

Through harmonic current rejection analysis, the generated harmonic current 


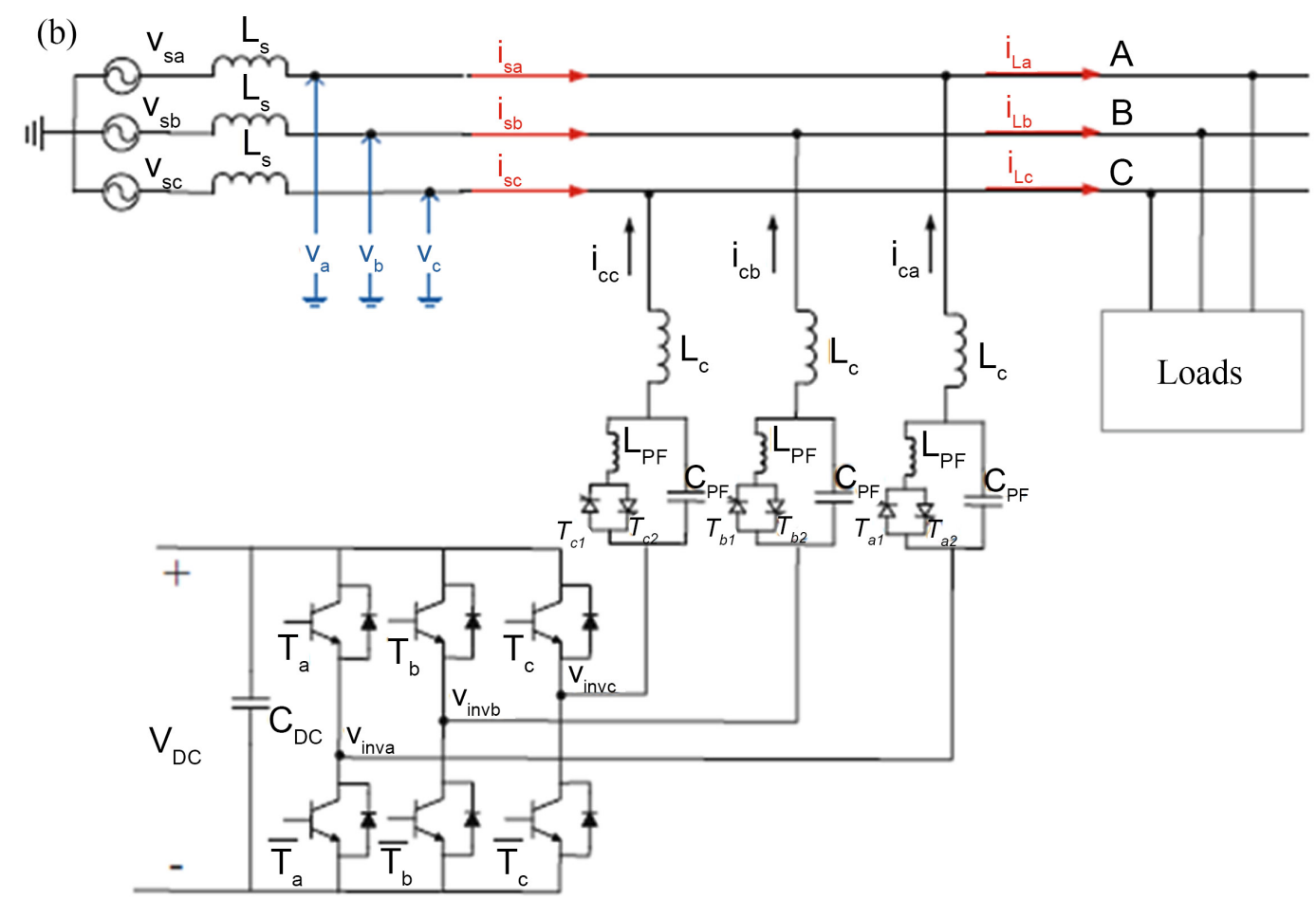

Figure 2. TCLC-HAPF filter structure.

orders can then be deduced in terms of LC. Therefore with proper LC design, the harmonic current injection by the controlled TCLC part can be reduced. Figure 3 illustrates the single phase equivalent model of the TCLC part for harmonic current rejection analysis. From Figure 3, when the switch $S$ is open, the differential equation of $i_{c x(t)}$ can be obtained as:

$$
L_{c} \frac{\mathrm{d} i_{c x(t)}}{\mathrm{d} t}+\frac{1}{C_{P F}} \int i_{C_{P F}}(t) \mathrm{d} t=V x_{(t)}
$$

Furthermore, when the switch is closed, the following relationships can be obtained:

$$
\begin{gathered}
L_{c} \frac{\mathrm{d} i_{c x(t)}}{\mathrm{d} t}+\frac{1}{C_{P F}} \int i_{C_{P F}}(t) \mathrm{d} t=V x_{(t)} \\
L_{P F} \frac{\mathrm{d} i_{L P F(t)}}{\mathrm{d} t}=\frac{1}{C_{P F}} \int i_{C_{P F}}(t) \mathrm{d} t \\
i_{L P F}+i_{C P F}=i_{C x}
\end{gathered}
$$

From relation (2.2) and (2.4) we get the equation in term $i_{C x(t)}$ by the relation:

$$
L_{c} L_{P F} C_{P F} \frac{\mathrm{d} i_{c x(t)}^{3}}{\mathrm{~d} t^{3}}-L_{P F} C_{P F} V x_{(t)} \frac{\mathrm{d} i_{c x(t)}^{2}}{\mathrm{~d} t^{2}}+\left(L_{c}+L_{c}\right) \frac{\mathrm{d} i_{c x(t)}}{\mathrm{d} t}=V x_{(t)}
$$

For relations (2.1) and (2.5) the compensation current $i_{C x}$. When $S$ is open is a second order equation. So much disk $i_{C x}$ when $S$ is closed it is a third order equation. The solutions of these differential equations can be deduced by solving 


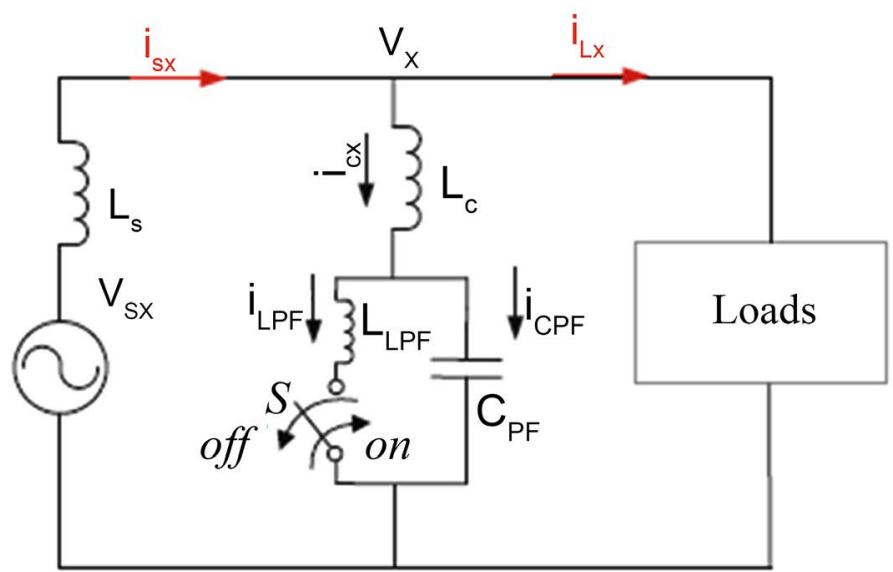

Figure 3. Single-phase equivalent model of the TCLC part.

these differential equations or via the Laplace transform. Solutions can be expressed in the form:

$$
i_{\text {Cx off }}=A_{1} \sin (w t-\alpha)+K_{1} \sin \left(w_{1} t-\varphi_{1}\right)
$$

Fundamental harmonic

$$
i_{C x o n}=A_{2} \sin (w t-\alpha)+K_{2} \cos \left(w_{2} t-\varphi_{2}\right)
$$

where $A_{1}$ and $A_{2}$ are the peak values of the compensation current at each switch-off and on, $K_{1}, K_{2}, K_{3}, \varphi_{1}, \varphi_{2}$ are constants during each switching cycle and which depend on the initial current conditions of compensation and the value of the load voltage, $\omega$ is the fundamental angular frequency of the system with $\omega=2 \pi f$ and $f$ is the frequency of the system. From Figure 3, we can deduce the impedance of the TCLC, knowing that $L_{c}\left(X_{l c}\right)$ is in series with the parallel combination of an $L_{P F}\left(X_{T C R(x)}\right)$ and $C_{P F} \quad\left(X_{C P F}\right)$

The result:

$$
X_{T C L C a f\left(\alpha_{a}\right)}=\frac{\pi X_{l P F f} X_{c P F f}}{X_{c P F f}\left(2 \pi-2 \alpha_{x}+\sin 2 \alpha_{x}\right)-\pi X_{l P F f}}+X_{L C}
$$

with:

$X_{L C}, X_{C P F}, X_{L P F}$ are impedances of the coupling inductor $L_{C}$, the capacitor $C_{P F}$ and the inductor $L_{P F} ; \alpha_{x}$ is the firing angle of the thyristor. This leads us to the following equivalent single-phase diagram: (Figure 4).

The active filter functions as a voltage generator and the indicated voltage value $V_{A F}$ is equivalent to the product of a gain $K_{c}$ by the harmonic component at the current source $i_{\text {sha }}$. Figure 5 shows the equivalent circuit with respect to harmonics

In the case where the active filter is not connected, that is to say when $K_{c}=0$ assuming that the source voltage is balanced and sinusoidal, the harmonic current $i_{\text {sha }}$ is then defined by the relation:

$$
i_{\text {sha }}=\frac{X_{\text {TCLCaf }}}{X_{L C}+X_{\text {TCLCaf }}} i_{c h}
$$




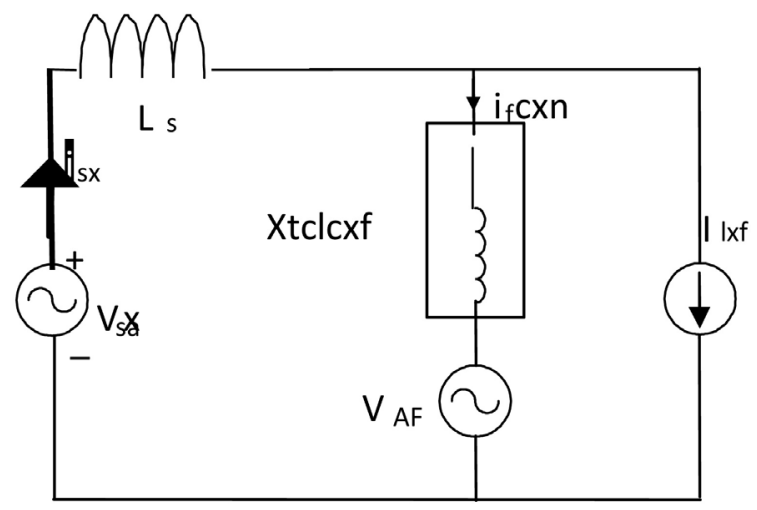

Figure 4. Simplified single-phase equivalent diagram.

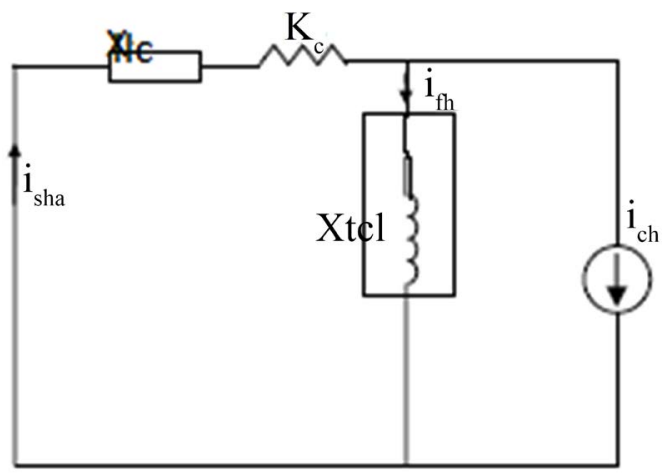

Figure 5. Equivalent diagram of the harmonic system.

when the active filter is connected and $K_{c} \neq 0$, it will therefore contribute with the passive filter to the absorption of the harmonic currents of the load on a therefore:

$$
i_{\text {sha }}=\frac{X_{\text {TCLCaf }}}{K_{c}+X_{L C}+X_{T C L C a f}} i_{c h}
$$

The relationship between the voltage displayed by the filter and the harmonic component of the source current $i_{\text {sha }}$ is:

$$
\begin{gathered}
V_{A F}=i_{\text {sha }}^{*} K_{c} \\
V_{A F}=\frac{X_{T C L C a f} K_{c}}{K_{c}+X_{L C}+X_{T C L C a f}} i_{c h}
\end{gathered}
$$

The active filter acts like a $K_{c}$ which attenuates the harmonic resistance currents by presenting a high resistance with regard to the latter. If $K_{c}$ is large compared to $X_{\text {TCLCaf }}$, the harmonic currents absorbed by the load will therefore mainly pass through the TCLC filter. If $K_{c}$ is large in front of $X_{l c}$, the value $K_{c}$ will then determine the performance of the filtering. If $K_{c}$ tends to infinity, then $i_{\text {sha }}$ tends to 0 and the filtering is then perfect.

\subsubsection{Configuration of the Thyristor Controlled Lc Coupled Hybrid Active Power Filter (TCLC-HAPF) with Control Unit}

Among all the topologies of hybrid filters [23], [20] we are interested here in the 
TCLC-HAPF composed of four parts:

- The three-phase supply network,

- The non-linear load symbolized by a diode bridge discharging in a load $\mathrm{R}$,

- The hybrid filter (inverter with voltage structure associated with a three-phase passive filter TCLC,

- The hybrid filter control.

This TCLC-HAPH is made up of a three-phase active filter with a voltage structure and a three-phase passive filter, tuned to a 5th harmonic. These two filters are connected in series without a transformer and the assembly is then connected in parallel on the network as shown in Figure 6. The passive filter absorbs the 5th harmonic currents to which it is tuned generated by the load and the active filter improves the efficiency of the passive filter

\subsection{Ordering the TCLC-HAPF}

Several methods of controlling the hybrid filter have been studied in the literature. For this work we study the so-called classical control scheme based on the $d-q$ transformation and the $\alpha-\beta$ transformation in two loops. For this purpose we use the transformations of Park and Concordia for the feedback loop and the feedforward loop.

\subsubsection{Classic Control Diagram}

Figure 6 shows the classic global control diagram and its two control loops. The PLL has two signals, at fundamental frequency and at harmonic frequency five. They will be used respectively in the feedback and feedforward loop.

\subsubsection{Classic Command Strategy}

The control strategy is the subject of our study on the hybrid filter, but being to improve the characteristics of the filtering while using a control method of reduced complexity. For both control loops, we use the SRF method to identify the voltage references of the inverter. For this, three quantities are measured:

- Source currents for the feedback loop,

- The load currents for the feedforward loop,

- Source voltages for the PLL.

The principle of this method is based on the use of a PLL to determine the components of $d-q$ axes of currents and voltages in Park's coordinate system. We can then extract the alternative components using two first order high pass filters for the feedback loop, and extract the continuous components using two first order low pass filters for the feedforward loop. The two types of extraction filters and the associated notations are published in Figure 7.

The general expression of the first order high pass filter is given by the following equation

$$
F_{F P H(S)}=\frac{S}{S+W_{c}}
$$

For the first order low pass filter, the expression is: 


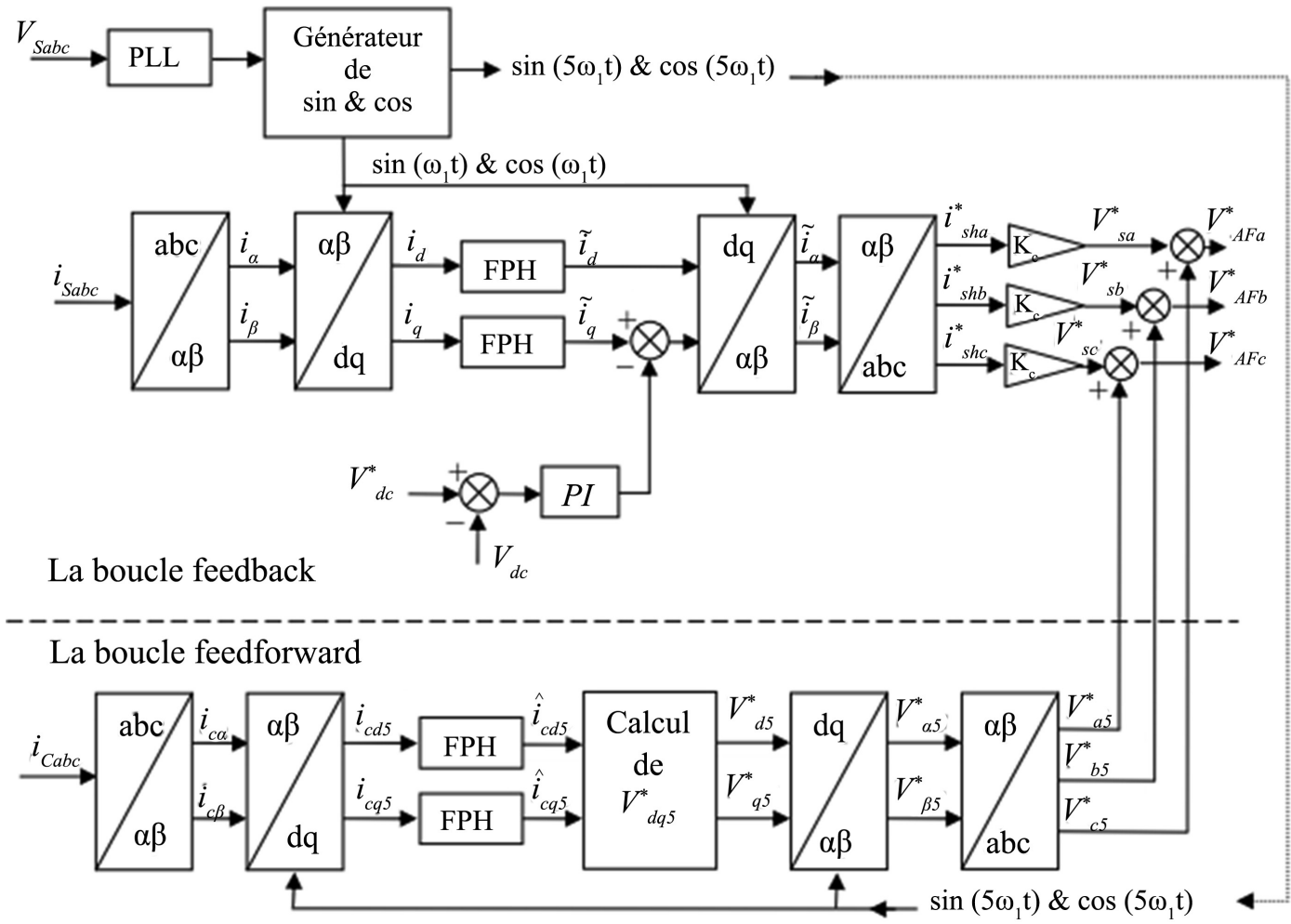

Figure 6. Classic control diagram of the Adaptive Hybrid filter.

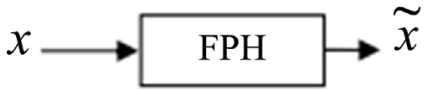

(a)

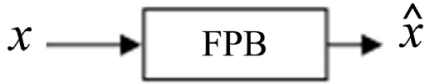

(b)

Figure 7. Extraction filter of the harmonic (a) and continuous (b) component.

$$
F_{F P H(S)}=\frac{W_{s}}{S+W_{c}}
$$

with: $W_{c}=2 \pi f_{c}$

We will now study in detail the two loops, feedback and feedforward. The impedance of the TCLC filter is given by the following expression

$$
X_{T C L C a f\left(\alpha_{a}\right)}=\frac{\pi X_{l P F f} X_{c P F f}}{X_{c P F f}\left(2 \pi-2 \alpha_{x}+\sin 2 \alpha_{x}\right)-\pi X_{l P F f}}+X_{L C}
$$

and the voltage is defined by:

$$
V_{d q 5}^{*}=X_{T C L C} * \hat{i}_{c d q 5}
$$

Then, we apply the inverse transformation $d-q$, which allows to determine the harmonic voltages of reference in the reference mark $\alpha-\beta$

$$
\left[\begin{array}{c}
V_{\alpha 5}^{*} \\
V_{\beta 5}^{*}
\end{array}\right]=\left[\begin{array}{cc}
\cos \left(\omega_{5} t\right) & -\sin \left(\omega_{5} t\right) \\
\sin \left(\omega_{5} t\right) & \cos \left(\omega_{5} t\right)
\end{array}\right]\left[\begin{array}{c}
V_{d 5}^{*} \\
V_{q 5}^{*}
\end{array}\right]
$$

The three-phase voltage references $V_{a b c 5}^{*}$ of the feedforward loop are then 
obtained after application of the reverse transformation of Concordia

$$
\left[\begin{array}{l}
V_{a 5}^{*} \\
V_{b 5}^{*} \\
V_{c 5}^{*}
\end{array}\right]=\sqrt{\frac{2}{3}}\left[\begin{array}{cc}
1 & 0 \\
-\frac{1}{2} & \frac{\sqrt{3}}{2} \\
-\frac{1}{2} & -\frac{\sqrt{3}}{2}
\end{array}\right]\left[\begin{array}{l}
V_{\alpha 5}^{*} \\
V_{\beta 5}^{*}
\end{array}\right]
$$

Finally, we add these three feedforward loop voltage references to the feedback loop voltage references to get the three active filter voltage references. Then, each reference voltage $V_{A F}^{*}$ is compared with a triangular signal (here, of frequency equal to $10 \mathrm{kHz}$ ) to produce the control orders of the power semiconductors of type THYRISTORS.

\subsubsection{Continuation of Reference Currents}

After determining the reference currents, the HAPF output currents are checked so that they follow their references as closely as possible. The control can be done by two main methods, namely:

- Control by hysteresis.

- Modulated hysteresis control

\section{1) Control by hysteresis:}

The hysteresis control, also called all or nothing control, is a nonlinear control. Its principle consists in first establishing the error signal which is then compared to a template called the hysteresis band. As soon as the error has reached the lower or upper band, a command is sent to stay within the band, represented by Figure 8 .

\section{2) Modulated hysteresis control:}

The modulated hysteresis control enables the switching frequency of the semiconductors to be set. This command consists in adding to the error signal $\varepsilon$ $\left(\varepsilon=i_{\text {fref }}-i_{f}\right)$ a triangular signal $\left(S_{t r}\right)$, of frequency $f_{t r}$ and Amplitude $A_{t r}$. The frequency $f_{t r}$ must be chosen equal to the switching frequency that one wishes to impose on the power components. The resulting signal then drives the input of a $2 \mathrm{Bh}$ bandwidth hysteresis regulator whose output is used to control the power switches. Figure 9 shows the principle of this command

\section{3) DC voltage regulation $V_{d c}$}

We have used a proportional integral regulator (PI) so that the average voltage across the capacitor is kept at a nearly constant value. The value of the evaluated voltage $V_{d c}$ is compared to its reference $V_{d c}^{*}$. The error signal is then applied to the input of the PI regulator.

\section{4) Determining the PI regulator parameters}

The following relation gives the general expression of the PI regulator used in our study

$$
K_{(s)}=\frac{K_{p} S+K_{i}}{s}
$$

$K_{p}$ : Proportional regulator gain 


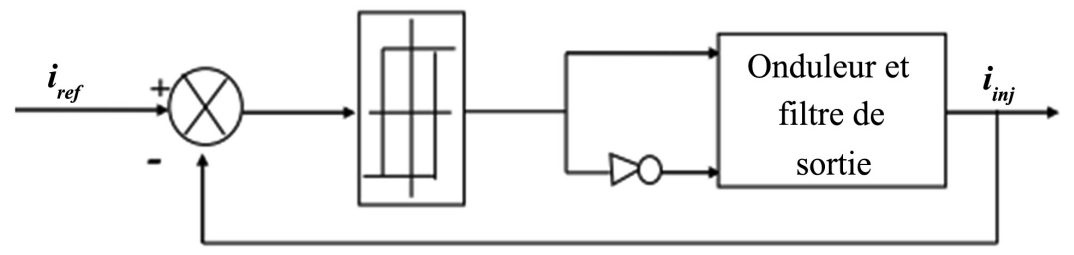

Figure 8. Diagram of the hysteresis control.

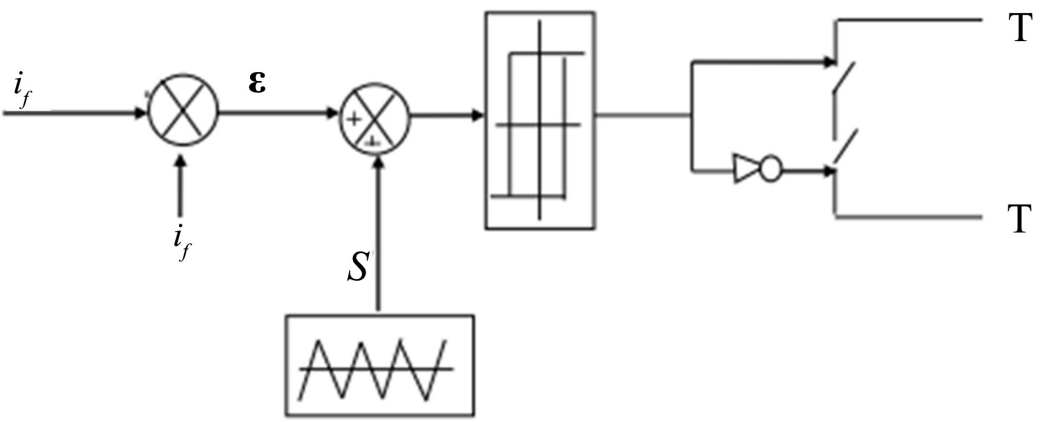

Figure 9. Diagram of modulated hysteresis control.

$K_{i}$ : Integral gain of the regulator

Figure 10 shows the $V_{d c}$ regulation diagram

The $G_{(s)}$ block is defined by:

$$
G_{(s)}=\frac{1}{C_{S}}
$$

The closed loop transfer function is then given by

$$
F(s)=\frac{\left(1+\frac{k_{p}}{k_{I}} s\right) \frac{k_{I}}{C}}{s^{2}+\frac{k_{p}}{C} s+\frac{k_{I}}{C}}
$$

The general expression of a second order transfer function is:

$$
F(s)=\frac{\left(1+\frac{k_{p}}{k_{I}} s\right) \omega_{c}^{2}}{s^{2}+2 \xi_{c} \omega_{c} s+\omega_{c}^{2}}
$$

After identification with Equation (2.26),

$$
K_{I}=\omega_{c}^{2} \times C \text { et } K_{P}=2 \xi_{c} \sqrt{K_{I} C}
$$

We chose: $\omega_{c}=2 \pi \times 18 \mathrm{rad} / \mathrm{s}$ et $\xi_{c}=0.6$.

\section{Simulation Results}

In this section, it is important to recall the spirit of the research carried out in this work:

1) Check the evolution of the current spectrum on the load side in the case of balance and imbalance by presenting the THD each time at the clearly stated position. 


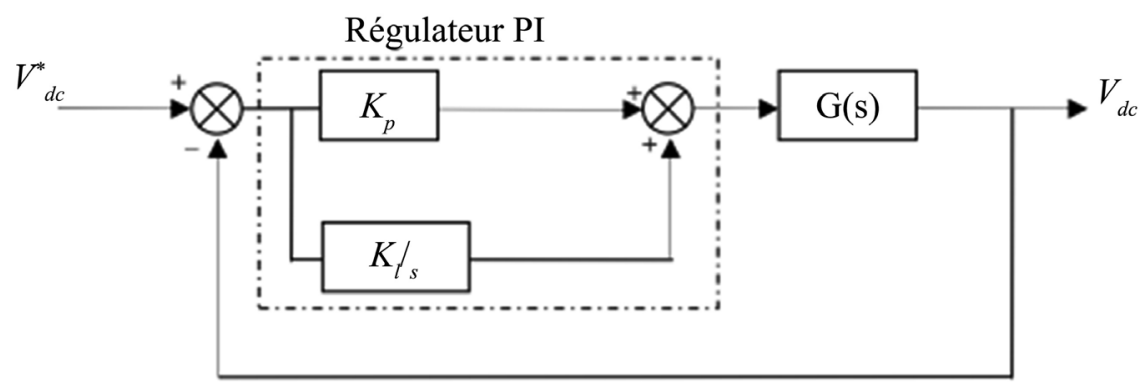

Figure 10. Diagram of Vdc regulation by a PI regulator.

2) Check the amount of current injected by the TLC-HAPF hybrid filter during variations in the network operating hypotheses with a real-time estimate of its THD.

3) Check the evolution of the current spectrum on the source side in the case of balance and unbalance by presenting the THD each time at the clearly stated position.

4) Evaluate the performance statistics of the TLC-HAPF filter over time in general.

\subsection{Simulink Model without Filter (Table 1 \& Figure 11)}

\subsubsection{Balanced Network}

Figure 12 shows the three voltages of the balanced network of the different phases $\mathrm{A}, \mathrm{B}$ and $\mathrm{C}$.

Figure 13 shows the source current Isa of phase A. Phases B and C are not shown because the loads are balanced.

Figure 14 shows the source current of phase $\mathrm{A}=$ phase $\mathrm{B}=$ phase $\mathrm{C}$ having for $\mathrm{THD}=30.88 \%$ over 5 cycles because the loads are balanced.

\subsubsection{Network with Unbalanced Loads}

The simulation parameters are as follows: (Figure 15).

$$
\mathrm{Vs}=380 \mathrm{~V} ; \mathrm{f}=50 \mathrm{~Hz} ; \mathrm{Ld}=1 \mathrm{mh} ; \mathrm{Rd}=30 \Omega ; \mathrm{R} 1=21 \Omega ; \mathrm{R} 2=10 \Omega ; \mathrm{R} 3=25
$$
$\Omega$;

Note: The same model is shown as in balanced regime, but the imbalance is illustrated by an unbalanced resistive three-phase load connected in parallel with our non-linear load.

Figure 16 shows the harmonic spectrum of the source current of phase A with its THD equal to $18.80 \%$. Also on 5 cyles.

Figure 17 shows the harmonic spectrum of the source current of phase B with its THD equal to $23.58 \%$. Pour 5 cycles.

Figure 18 shows the harmonic spectrum of the source current of phase $\mathrm{c}$ with its THD equal to $32.71 \%$. Pour 5 cyles (Table 2).

\subsection{Simulink Model with TLC-HAPF Filter (Figure 19)}

The filter parameters used in the rest of our work have become in the following Table 3. 
Table 1. Parameters of the system to be simulated.

\begin{tabular}{cccc}
\hline Vs & f & Rd & Ld \\
\hline $\mathbf{3 8 0} \mathrm{V}$ & $50 \mathrm{~h}_{\mathrm{z}}$ & $30 \Omega$ & $1 \mathrm{mh}$ \\
\hline
\end{tabular}

Table 2. Summary table of the two cases.

\begin{tabular}{ccc}
\hline & THD For balanced loads & THD For unbalanced loads \\
\hline PHASE A & $30.88 \%$ & $18.80 \%$ \\
PHASE B & $30.88 \%$ & $23.58 \%$ \\
PHASE C & $30.88 \%$ & $32.71 \%$ \\
\hline
\end{tabular}

Table 3. Parameters of the system to be simulated.

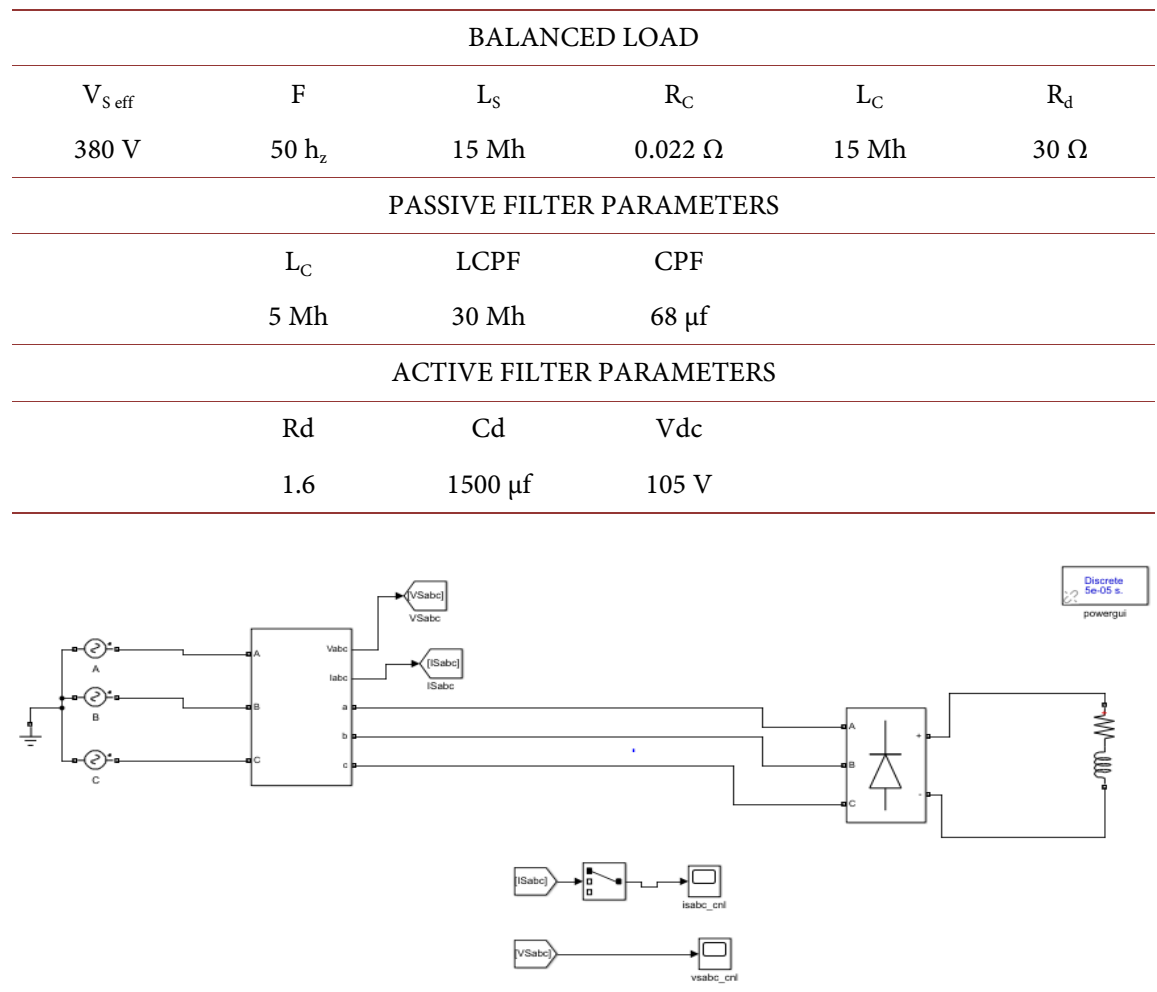

Figure 11. Simulink whole network nonlinear load model.

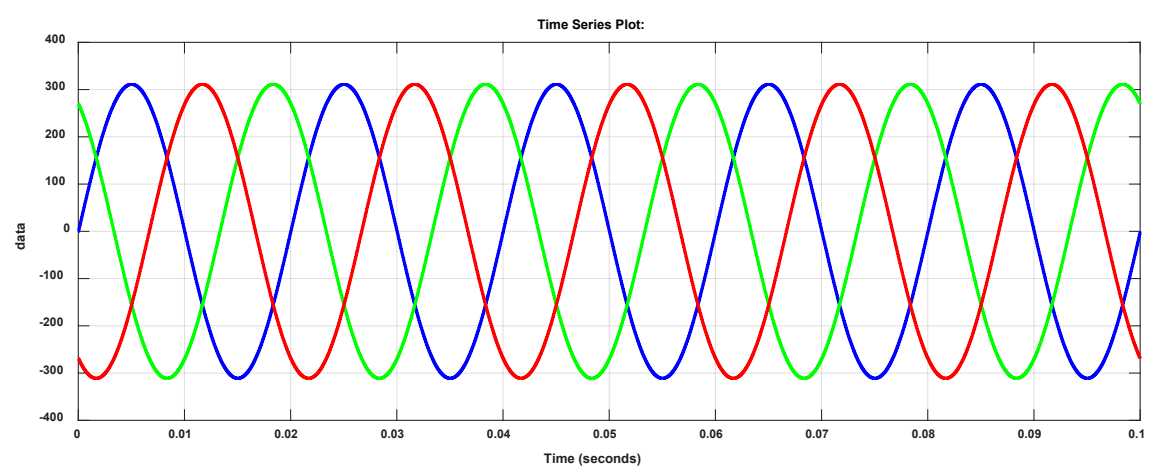

Figure 12. Tension source réseau équilibré. 


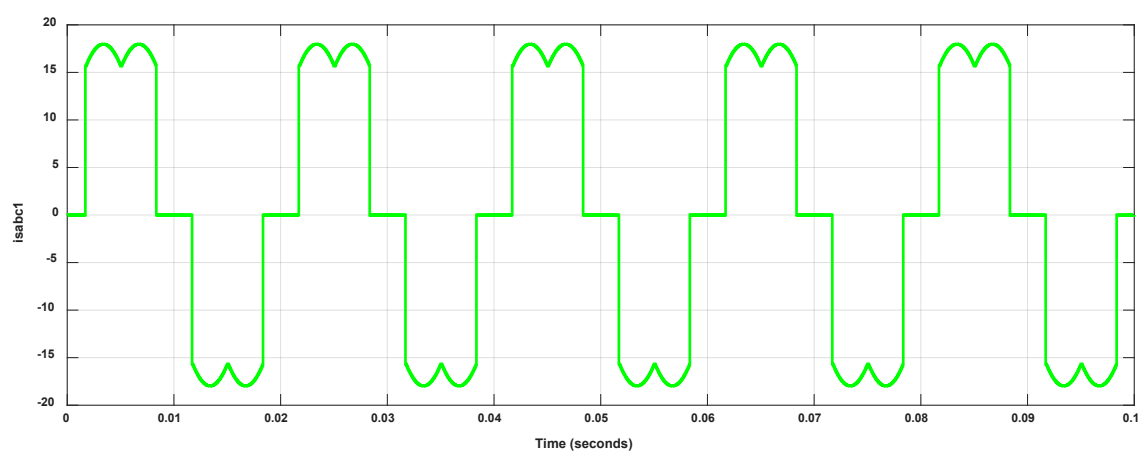

Figure 13. Balanced mains source current.
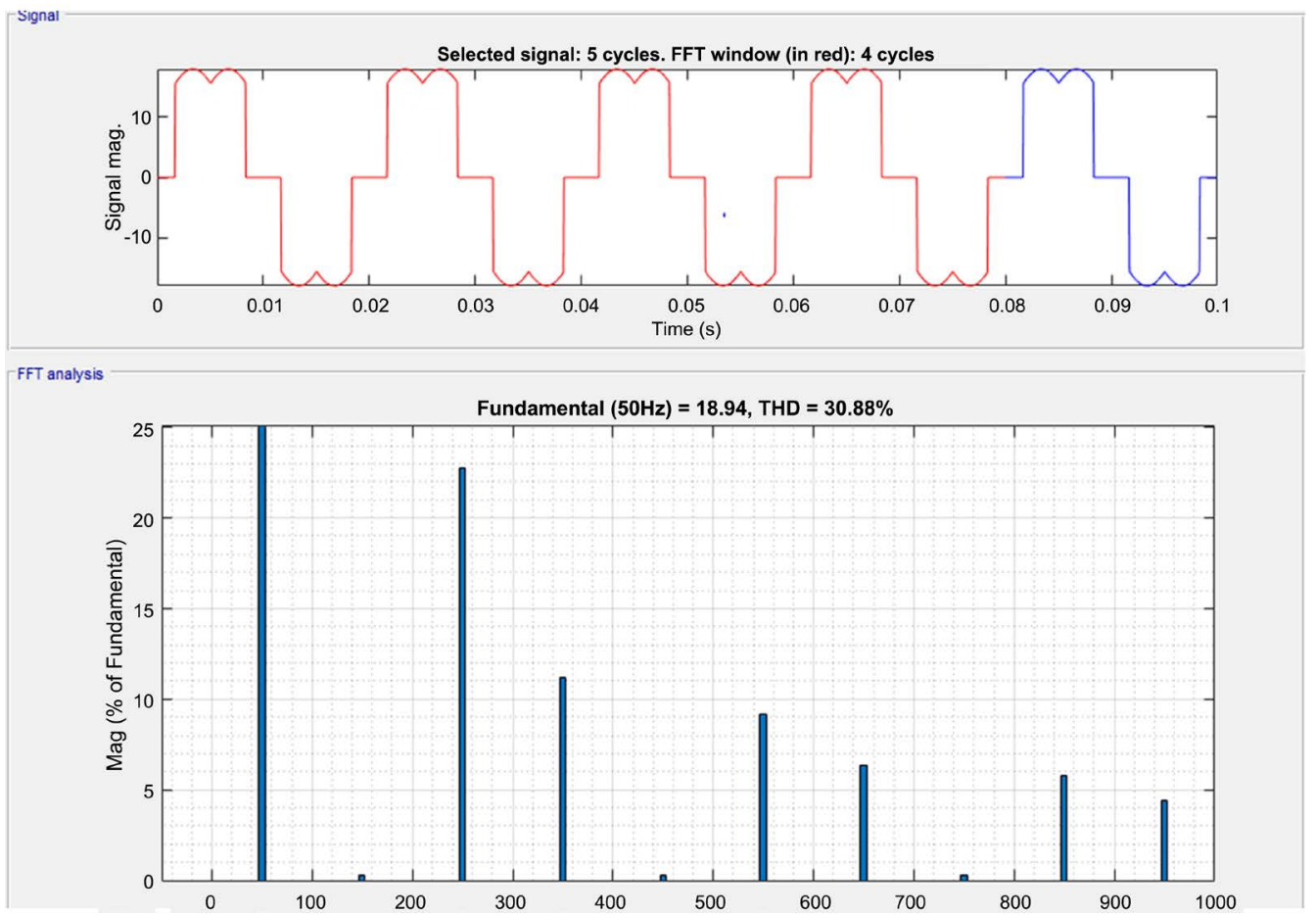

Figure 14. Harmonic spectrum of the balanced mains source current.

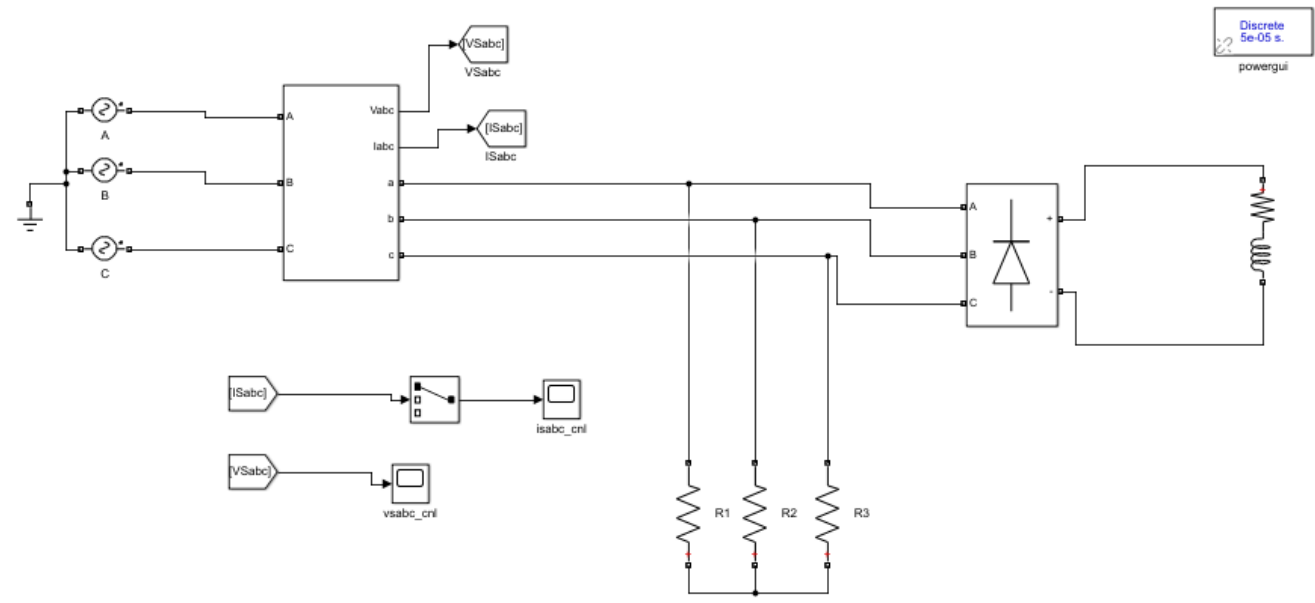

Figure 15. Simulink model of unbalanced loads, three-phase network, non-linear load. 

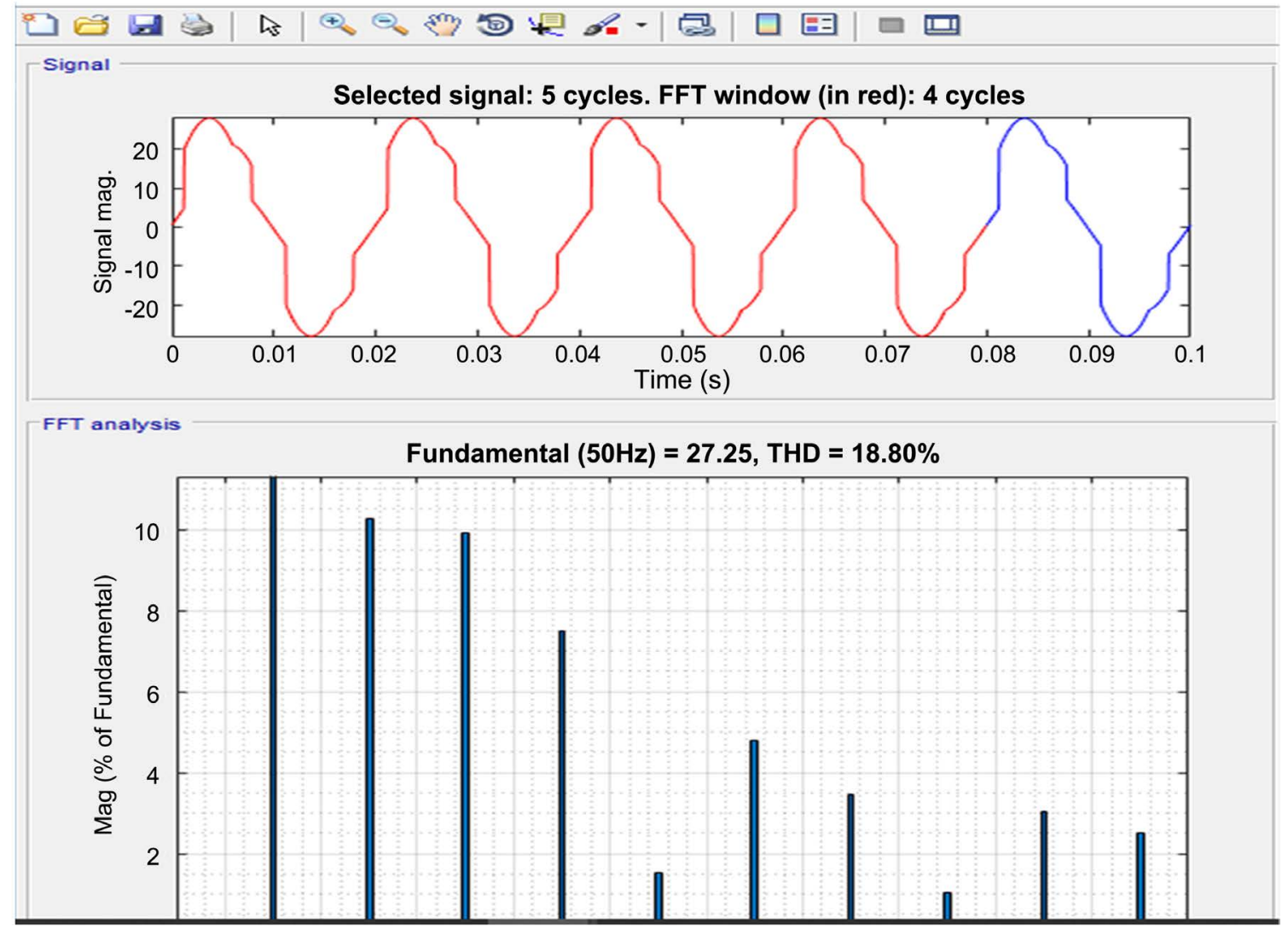

Figure 16. Harmonic spectrum of the source phase A current.

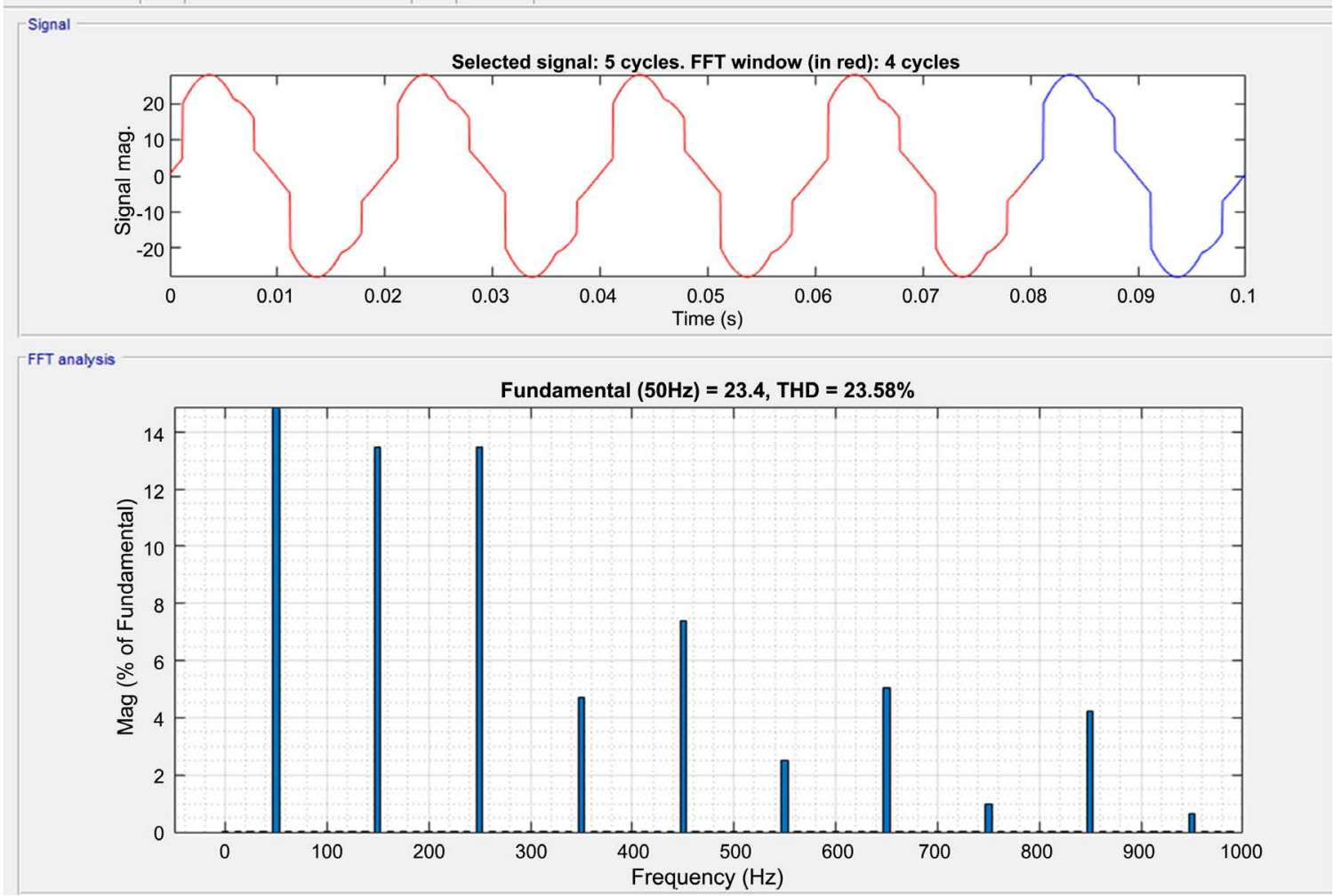

Figure 17. Harmonic spectrum of the phase B source current. 


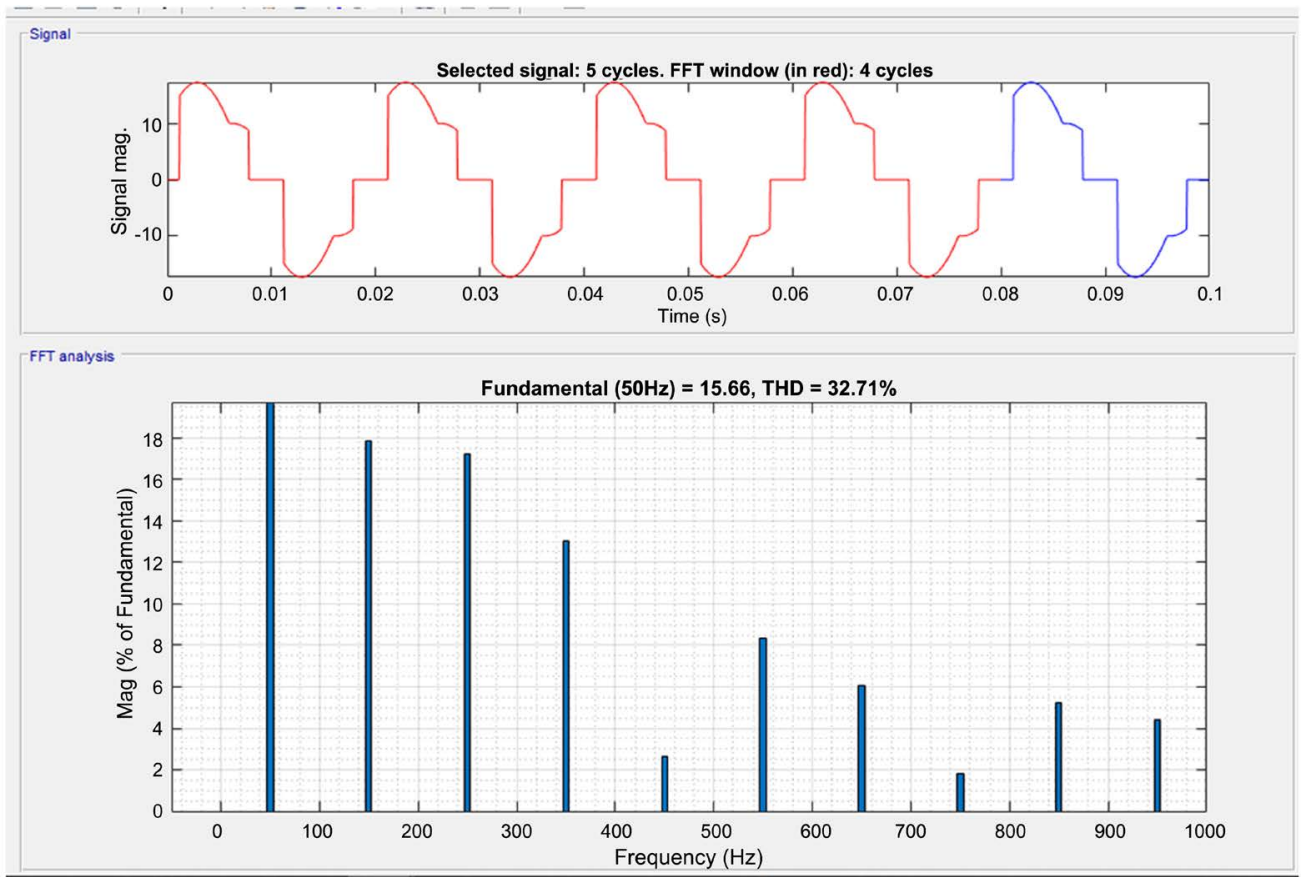

Figure 18. Harmonic spectrum of source current phase c.

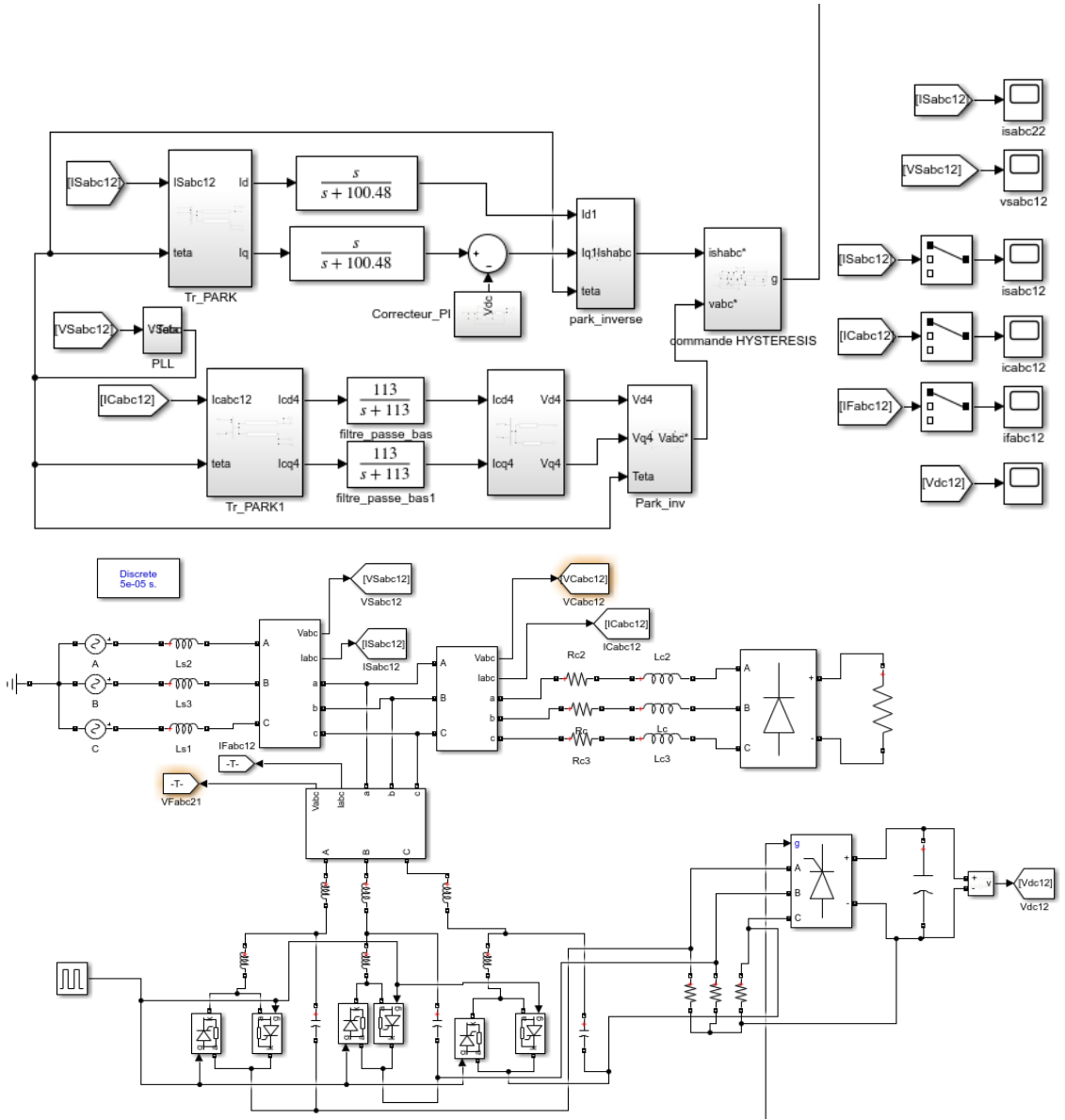

Figure 19. Simulink three-phase network model with TLC-TLC-HAPF filter controlled by modulated hysteresis. 


\subsubsection{Network with Balanced Loads}

Figure 20 shows the harmonic spectrum of the current injected by the TLC-HAPF filter with its THD for the case of the balanced network which is at $44.60 \%$. This quantity of current injected by the filter into the network will have the task of stabilizing the disturbance from the load side.

Figure 21 shows the harmonic spectrum of the load current for the three phases which are balanced here and with its THD equal to $17.39 \%$. For 5 cycles.

Figure 22 shows the harmonic spectrum of the phase source current with its THD equal to $3.71 \%$ after filtering.

The TLC-HAPF filter gives us a value of $3.71 \%$ for a Vdc voltage of $105 \mathrm{~V}$. This result complies with the Limits of distortion of voltages at Pcc (IEEE 519-1996) for voltages below $69 \mathrm{kv}$, for a THD between 3\% and 5\%. It is also reassured by the work of [1] on the admissible values after filtering (Table 4).

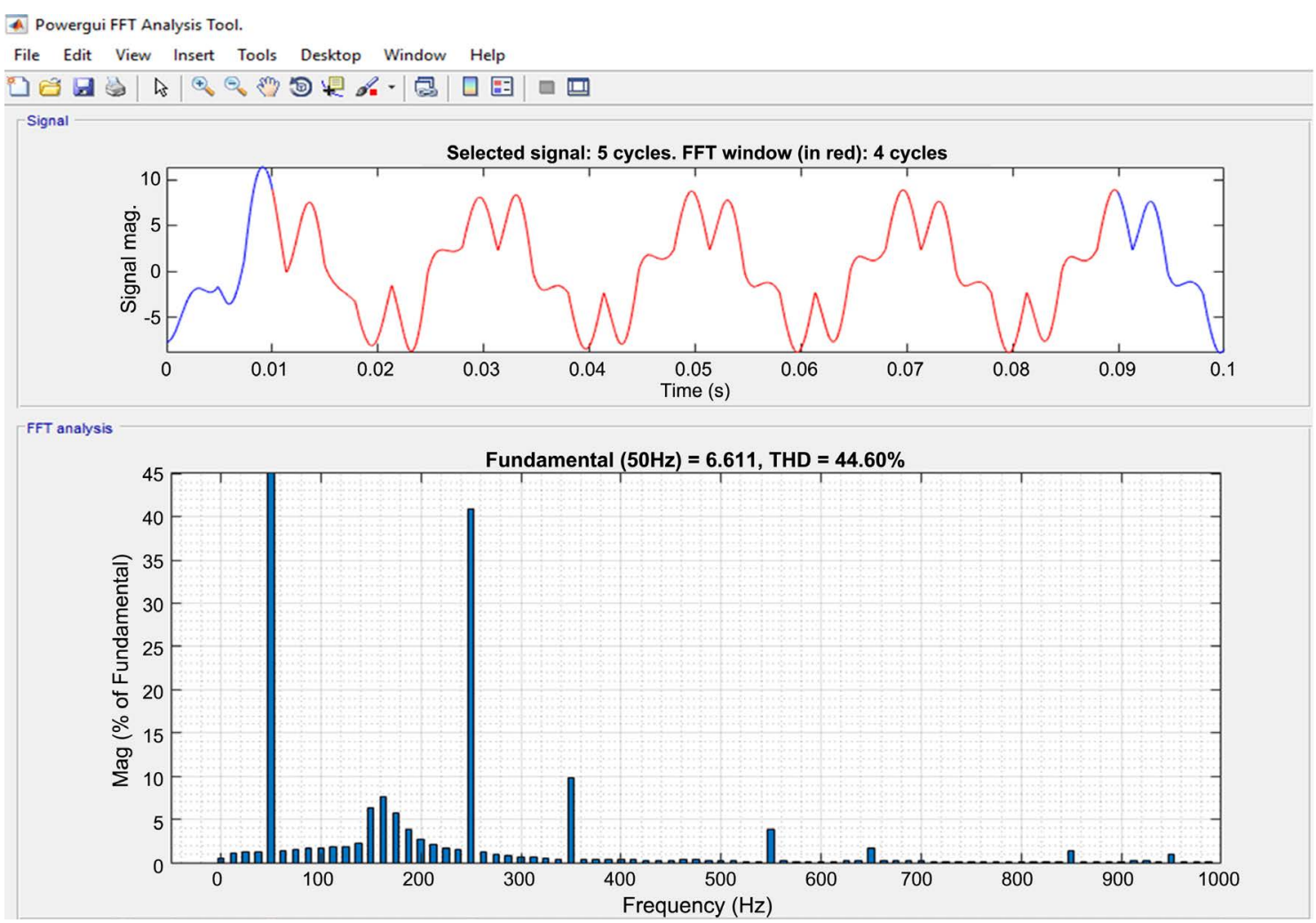

Figure 20. Harmonic spectrum of the current injected by the TLC-HAPF filter with its THD for the case of the balanced network.

Table 4. Summary table of system evolution 1.

\begin{tabular}{ccccc}
\hline & $\begin{array}{c}\text { THD Fee } \\
\text { For balanced } \\
\text { Before filtering }\end{array}$ & $\begin{array}{c}\text { THD of the current injected } \\
\text { By the filter TLC-HAPF for } \\
\text { system correction }\end{array}$ & $\begin{array}{c}\text { THD of the source } \\
\text { side current after } \\
\text { Filtering }\end{array}$ & $\begin{array}{c}\text { THD of the load side } \\
\text { current source after } \\
\text { Filtering }\end{array}$ \\
\hline PHASE A & $30.88 \%$ & $44.60 \%$ & $3.71 \%$ & $17.39 \%$ \\
PHASE B & $30.88 \%$ & $44.60 \%$ & $3.71 \%$ & $17.39 \%$ \\
PHASE C & $30.88 \%$ & $44.60 \%$ & $3.71 \%$ & $17.39 \%$ \\
\hline
\end{tabular}




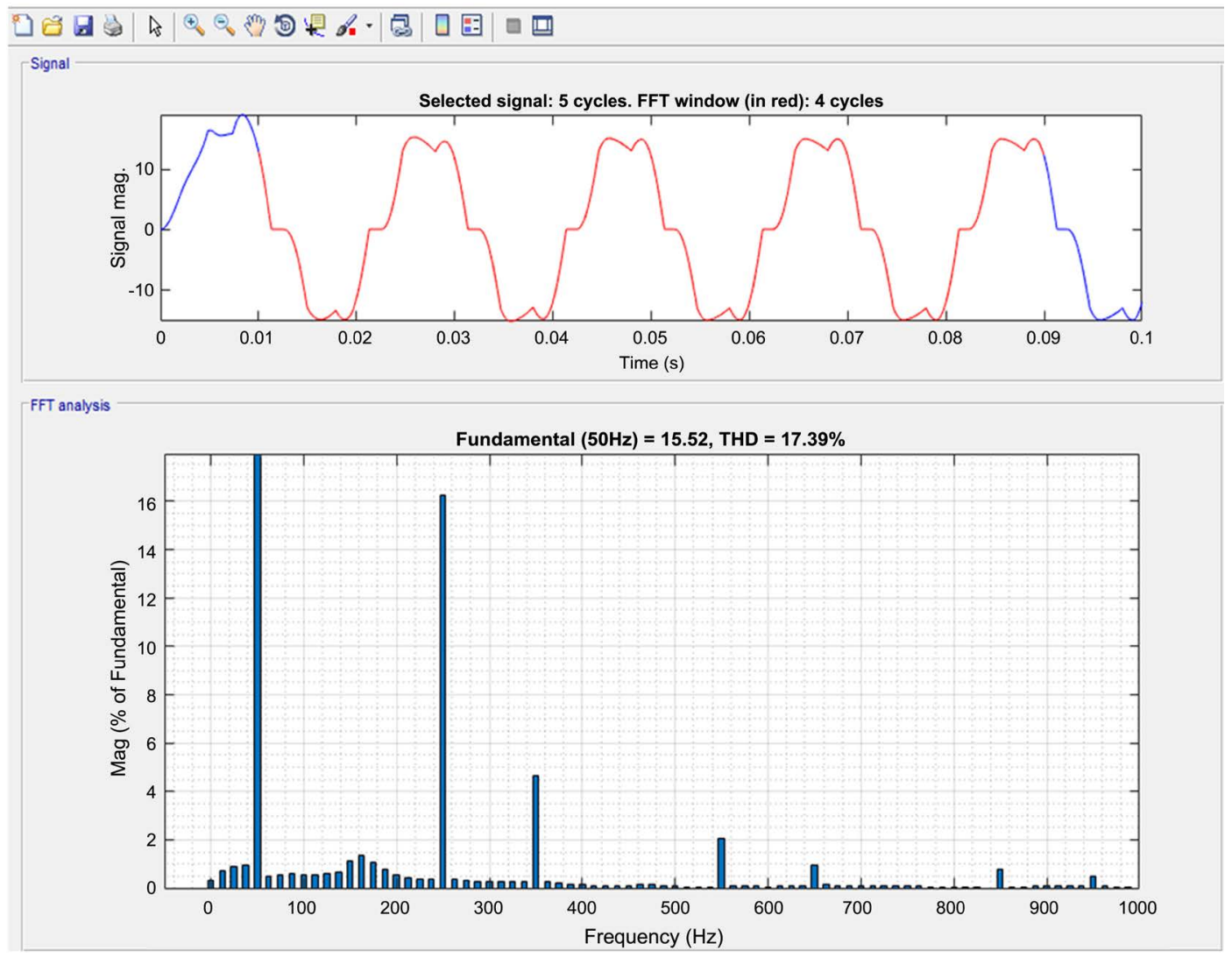

Figure 21. Harmonic spectrum of the load side current with THD in the case of a balanced network.

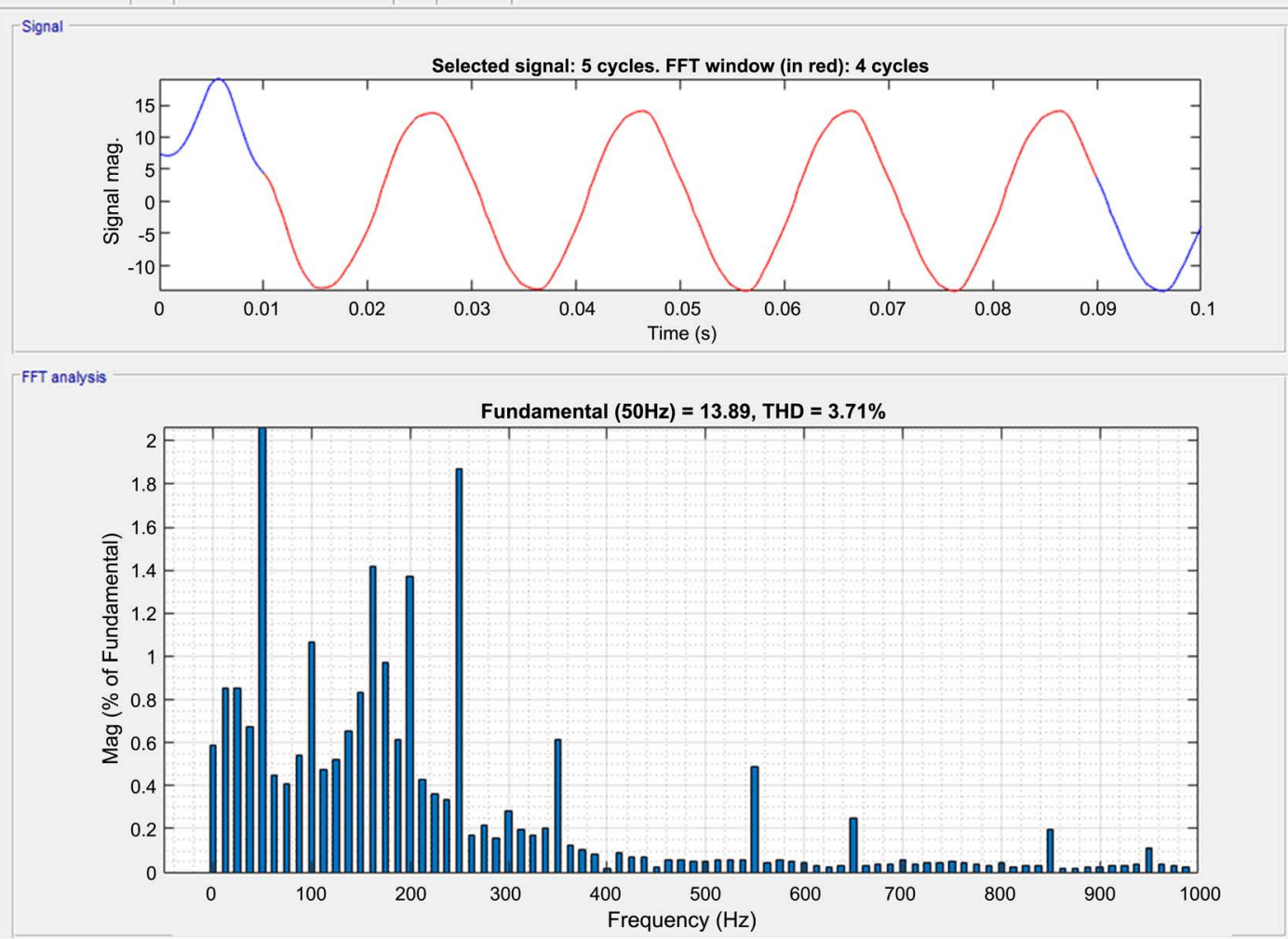

Figure 22. Harmonic spectrum of the source side current with balanced network THD. 


\subsubsection{Network with Unbalanced Loads}

The simulation parameters are the same as those in Table 3. In addition on a: R1 $=21 \Omega \mathrm{R} 2=10 \Omega \mathrm{R} 3=25 \Omega$.

The current amplitudes of the three phases A, B, C varying between 10, 13, 18 A proof that the TLC-HAPF filter succeeds in adjusting the intensity according to the disturbance or imbalance of the system.

Figures 23-25 respectively show the currents injected by the TLC-HAPF filter into the network from which we have the values in THD for the particular case of injection currents. Thanks to our experimental platform Simulink we also obtain the other values in THD source dimension after filtering, values presented in the following Table 5.

Table 5. Summary table of system evolution 2 .

\begin{tabular}{cccc}
\hline & $\begin{array}{c}\text { THD Fee For Unbalanced } \\
\text { Before filtering }\end{array}$ & $\begin{array}{c}\text { THD of the current injected } \\
\text { By the TLC-HAPF filter for } \\
\text { system correction }\end{array}$ & $\begin{array}{c}\text { THD of the source side } \\
\text { current after Filtering }\end{array}$ \\
\hline PHASE A & $18.80 \%$ & $39.15 \%$ & $2.08 \%$ \\
PHASE B & $23.58 \%$ & $41.66 \%$ & $1.70 \%$ \\
PHASE C & $32.71 \%$ & $33.32 \%$ & $1.33 \%$ \\
\hline
\end{tabular}

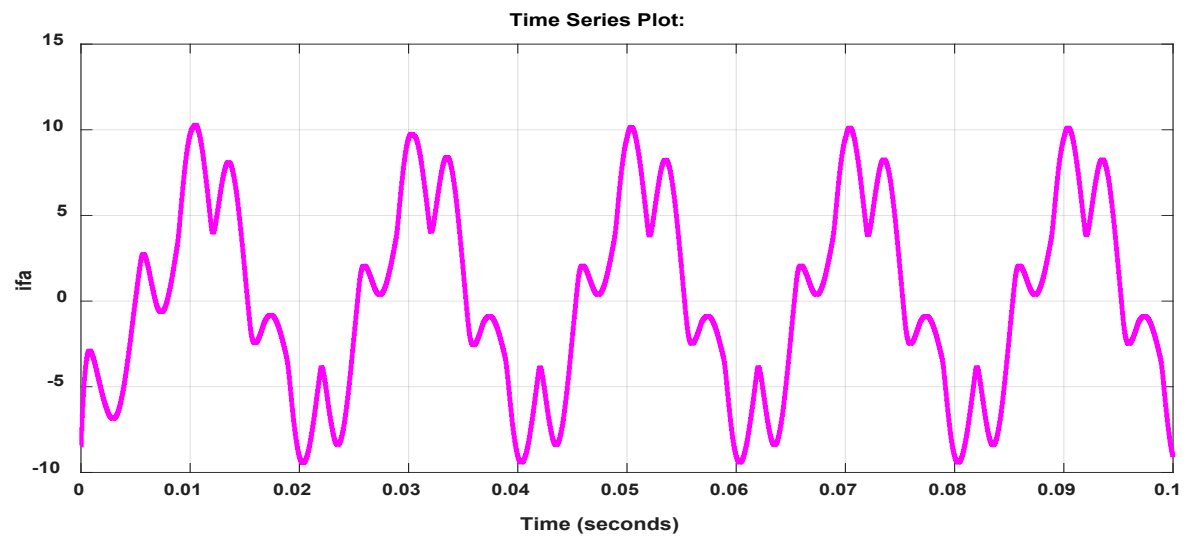

Figure 23. Filter current injected into phase A.

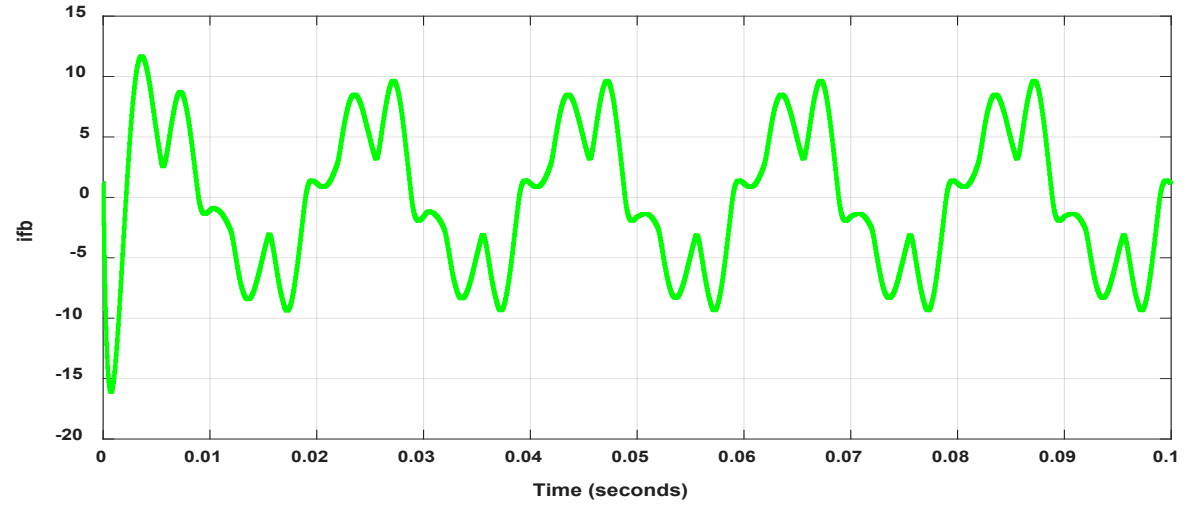

Figure 24. Filter current injected into phase B. 


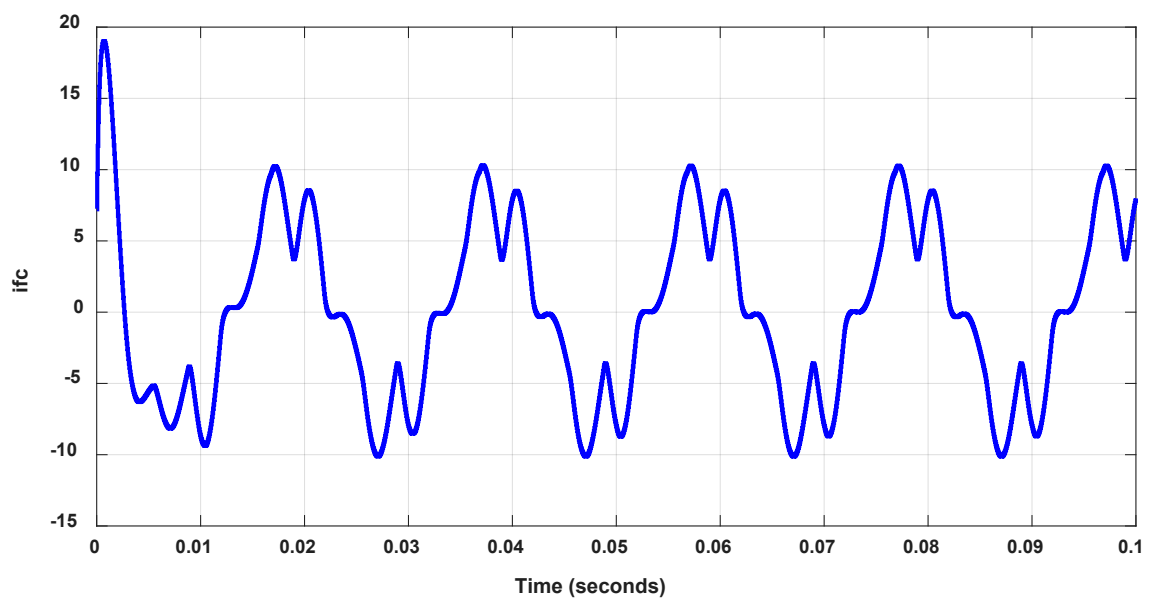

Figure 25. Filter current injected into phase C.

The TLC-HAPF filter gives us the values of $2.08 \%, 1.70 \%, 1.33 \%$ after filtering on the source side for a Vdc voltage of $105 \mathrm{~V}$. This result complies with the Limits of the distortions of voltages at Pcc (IEEE 519-1996) for voltages less than 69 $\mathrm{kv}$, for a THD between 3\% and 5\%. It is also reassured by the work of [1] on the admissible values after filtering. We also note that the filter resists imbalance very well and offers us quite interesting THDs. On the other hand, modulated hysteresis control

\section{Conclusion}

In this article, it was a question of highlighting the particularity of the TLC-HAPF architecture which offers advantages such as reducing or limiting switching losses during the injection of currents into the network thanks to its TLC module. This topology brings also solutions to dynamic performance issues, resonance and a lack of compensating capacity for cases of imbalance conditions. It also offers a greater compensation range than conventional active models that do not offer as well as a link voltage CC of the order $105 \mathrm{v}$ to $109 \mathrm{v}$ relatively inferior to the other models $(600 \mathrm{v})$. A control by modulated hysteresis of this topology was also developed in this paper and allows to obtain a functional analysis of the network on the three phases at three levels: source side, load side, and finally at the level of the connection of the filter to the networks by specifying each time the value of the spectrum of the current and its THD at this t time well defined. All of its particularities give the TLC-HAPF filter the ability to better resist disturbances and variations to which the network is subjected. With regard to its static performances, it becomes very interesting to compare its results obtained with a command by modulated hysterisia with an $\mathrm{H}$-infinite command, for example, which also presents certain particularities in its algorithm.

\section{Conflicts of Interest}

The authors declare no conflicts of interest regarding the publication of this paper. 


\section{References}

[1] Hanna Nohra, A.F. (2017) Commande de Filtres Actifs Parallèles sur un Réseau Fortement Perturbé: Doctorat De L'université De Toulouse le lundi 30 janvier.

[2] Hanna Nohra, A.F., Kanaan, H.Y. and Fadel, M. (2016) Comparative Evaluation of Harmonic Compensation Methods Based on Power Calculation and Current Harmonic Detection for Single-Phase Applications. IECON 2016 42nd Annual Conference of the IEEE Industrial Electronics Society, Florence, 23-26 October 2016, 3685-3690.

[3] Hanna Nohra, A.F., Fadel, M. and Kanaan, H.Y. (2019) Design of a Direct Control Strategy for a Static Shunt Compensator to Improve Power Quality in Polluted and Unbalanced Grids. Mathematics and Computers in Simulation, 158, 199-215.

[4] Hanna Nohra, A.F., Fadel, M. and Kanaan, H.Y. (2017) Direct Control of a Three-Phase Active Filter on a Disturbed Network. 43rd Annual Conference of the IEEE Industrial Electronics Society, Beijing, 29 October-1 November 2017, 95-100. https://doi.org/10.1109/IECON.2017.8217114

[5] Hanna Nohra, A.F., Fadel, M. and Kanaan, H.Y. (2016) A Novel Instantaneous Power Based Control Method for a Four-Wire SAPF Operating with Highly Perturbed Mains Voltages. IEEE International Conference on Industrial Technology (ICIT), Taipei, 14-17 March 2016, 36-41.

https://doi.org/10.1109/ICIT.2016.7474931

[6] Hanna Nohra, A.F., Fadel, M. and Kanaan, H.Y. (2014) A Control Strategy in Active Power Filter for Power Quality Improvement. The 2 nd IEEE Conference on Power Engineering and Renewable Energy, Bali, 9-11 December 2014, 192-198. https://doi.org/10.1109/ICPERE.2014.7067236

[7] Santos, E., Khosravy, M. and Lima, M.A.A. (2020) Esprit Associated with Filter Bank for Power-Line Harmonics, Sub-Harmonics and Inter-Harmonics Parameters Estimation. Electrical Power and Energy Systems, 118, Article ID: 105731. https://doi.org/10.1016/j.ijepes.2019.105731

[8] Shivaie, M. (2019) A Techno-Economic Multi-Objective Model for Hybrid Harmonic Filter Planning Considering Uncertainty in Non-Linear Loads. International Journal of Electrical Power and Energy Systems, 112, 339-352. https://doi.org/10.1016/j.ijepes.2019.05.013

[9] Guan, M. (2020) Harmonics Detection via Input Observer with Grid Frequency Fluctuation. International Journal of Electrical Power and Energy Systems, 115, Article ID: 105461. https://doi.org/10.1016/j.ijepes.2019.105461

[10] Marini, A., Ghazizadeh, M.-S. and Mortazavi, S.S. (2019) A Harmonic Power Market Framework for Compensation Management of DER Based Active Power Filters in Microgrids. International Journal of Electrical Power and Energy Systems, 113, 916-931. https://doi.org/10.1016/j.ijepes.2019.06.020

[11] Yang, L. (2020) 3D Modeling of an HVDC Converter Transformer and Its Application on the Electrical Field of Windings Subject to Voltage Harmonics. International Journal of Electrical Power and Energy Systems, 117, Article ID: 105581. https://doi.org/10.1016/j.ijepes.2019.105581

[12] Marinim, A. and Piegari, L. (2019) A Harmonic Power Market Framework for Compensation Management of DER Based Active Power Filters in Microgrids. International Journal of Electrical Power and Energy Systems, 113, 916-931. https://doi.org/10.1016/j.ijepes.2019.06.020

[13] Kapoor, R. (2011) Hybrid Demodulation Concept and Harmonic Analysis for Sin- 
gle/Multiple Power Quality Events Detection and Classification. International Journal of Electrical Power and Energy Systems, 33, 1608-1622. https://doi.org/10.1016/j.ijepes.2011.06.006

[14] Harrison, A. (2010) The Effects of Harmonics on Power Quality and Energy Efficiency.

[15] Manson, J. and Targosz, R. (2008) European Power Quality Survey Report.

[16] CEI 61000-3-2 Compatibilité électromagnétique (CEM)-Partie 3-2: Limites-Limites pour les émissions de courant harmonique (Courant appelé par les appareils 16A par phase) édition 3.2-2009.

[17] CEI 61000-2-2 Compatibilité Electromagnétique (CEM)-Partie 2-2: Environnement-Niveaux de compatibilité pour les perturbations conduites à basse fréquence et la transmission des signaux sur les réseaux publics d'alimentation basse tension. Deuxième édition 2002-03.

[18] IEC 61000-2-4 Compatibilité électromagnétique (CEM)-Partie 2-4: Environnement-Niveaux de compatibilité dans les installations industrielles pour les perturbations conduites à basse fréquence. Deuxième édition 2002-06.

[19] EN 50160:11-1999 “Voltage Characteristics of Electricity Supplied by Public Distribution Systems".

[20] IEEE Recommended Practice for Monitoring Electric Power Quality. IEEE Std 1159-2009 (Revision of IEEE Std 1159-1995), vol., no., pp. c1, 81, June 262009.

[21] Garcia, O., Cobos, J.A., Prieto, R., Alou, P. and Uceda, J. (2003) Single Phase Power Factor Correction: A Survey. IEEE Transactions on Power Electronics, 18, 749-755. https://doi.org/10.1109/TPEL.2003.810856

[22] Schneider Electric. Guide de l'installation électrique-2009.

[23] François Defaÿ Commande Prédictive Directe d'un Convertisseur Multicellulaire Triphasé Pour Une Application de Filtrage Actif. Université de Toulouse-Institut National Polytechnique de Toulouse-2008.

[24] Akagi, H. (1996) New Trends in Active Filters for Power Conditioning. IEEE Transactions on Industry Applications, 32, 1312-1322.

https://doi.org/10.1109/28.556633

[25] Kanaan, H.Y. and Al-Haddad, K. (2004) Comparative Evaluation of Average-Model-Based Control Schemes Applied to a Three-Phase Series Active Power Filter for Voltage Harmonic Cancellation. Proc. 13th IEEE International Symposium on Industrial Electronic (ISIE04), Ajaccio, 4-7 May 2004, Vol. 2, 783-789.

[26] Kanaan, H.Y., Mougharbel, I. and Al-Haddad, K. (2008) Average Modeling and Carrier-Based Control Strategies Applied to a Three-Phase Four-Leg Shunt Active Power Filter. International Review of Electrical Engineering (IREE), Praise Worthy Prize (PWP), 3, 443-451.

[27] Nohra, A.F.H., Kanaan, H.Y. and Al-Haddad, K. (2013) A Four-Leg Active Power Filter for Harmonic Mitigation and Reactive Power Compensation in Unbalanced Loads Systems Using CFL Technology. International Conference on Industrial Technology, Cape Town, 25-28 February 2013, 5-10. https://doi.org/10.1109/ICIT.2013.6505974

[28] Rachmildha, T.D., Llor, A., Fadel, M., Dahono, P.A. and Haroen, Y. (2007) Quasi Hybrid Direct Power Control on 3-Phase 4-Wire Active Power Filter. Proceedings of the International Conference on Electrical Engineering and Informatics, Bandung, 17-19 June 2007, 60-65.

[29] Rachmildha, T.D., Llor, A., Fadel, M., Dahono, P.A. and Haroen, Y. (2008) 3-Phase 
4-Wire Active Power Filter Using p-q-r Instantaneous Power Theory with Hybrid Approach. Jurtek UI, March 2008, 13-19.

[30] Rachmildha, T.D., Llor, A., Fadel, M., Dahono, P.A. and Haroen, Y. (2008) Hybrid Direct Power Control Using p-q-r Power Theory Applied on 3-Phase 4-Wire Active Power Filter. PESC2008, Conference Proceeding, Rhodes, 15-19 June 2008.

https://doi.org/10.1109/PESC.2008.4592090 